\title{
APPLICATION OF THE LAST PLANNER® SYSTEM IN A SPORTS INFRASTRUCTURE PROJECT IN PERU
}

\author{
Andrews A. Erazo-Rondinel ${ }^{1}$, Alfredo Vila-Comun ${ }^{2}$, and Abel Alva ${ }^{3}$
}

\begin{abstract}
The Last Planner System ${ }^{\circledR}$ (LPS) is been applied in Peru since the 2000s for many General Contractors (GC), mainly in the concrete frames phase of building projects. However, most of the problems with variability and coordination comes up during the MEP (Mechanical, Electrical, and Plumbing) phase and finishing works. The following paper sums up the application of The Last Planner on a large sports infrastructure project in Peru for the Pan-American Games focused on MEP phase and finishing works. It offers an overview of the implementation of LPS and its impact on the indicators of the project. This implementation took 27 weeks and was divided into two phases. The first phase took 10 weeks. Here, subcontractors discovered and learned about LPS. After this process the team evaluated the level of knowledge and identified opportunities to improve it. With this diagnose, the team implemented a set of measures to increase the level of LPS on the project. Finally, this implementation helped the project to reduce the variability (increase the Percentage of Complete Plan) and increase SPI (Schedule Performance Index), making it possible to deliver on time.
\end{abstract}

\section{KEYWORDS}

Last Planner® System, big room/obeya, pull planning, visual management, collaboration.

\section{INTRODUCTION}

The infrastructure of Pan-American Games was built in an incredible time and the Peruvian Government saved more than 250 million dollars, based in an agreement with the United Kingdom government, that permitted the transfer of know-how processes. One of these was NEC 3(New Engineering Contract), a new model of contract for engineering, procurement, and construction that helped to finish the venues on time. (Gestion, 2019).

COSAPI was the general contractor of THE VIDENA PROJECT, the center of the Pan-American games in Peru. They had a short time to design, construct, and operate all the sports centers for competence. As part of this management, COSAPI applies good practices of PMI (Project Management Institute) and Lean Construction to executed projects; to ensure the completion on the schedule COSAPI used Earned Value Management (EVM) and LPS to reduce the variability on the project. However, in Peru, LPS is not properly implemented. Several site engineers believe that by using only a few

1 Graduate Student, National University of Engineering, aerazor@uni.edu, orcid.org/0000-0002-5639$\underline{573 X}$

$2 \quad$ Projects Control Chief at Cosapi, avila@cosapi.com.pe, orcid.org/0000-0002-6621-834X

3 Field Engineer Chief at Cosapi, aalva@cosapi.com.pe, orcid.org/0000-0002-2233-1279 
tools, they're making an LPS-enabled project (Murguia, 2019). Also, Murguia et al. (2016) described that the Last Planner System (LPS) is widely implemented by contractors during structural work in Peru. However, during the finishing phase, its efficacy is reduced, as teams deal with high levels of variability, uncertainty within supply chains, and unpredictable production capacities among subcontractors.

This research described the implementation of LPS in finishing and MEP phase during the 27th weeks. It shows the application in 02 venues: Multisport 03 and the administration building, the aim of this research is: a) To show the implementation of The Last Planner System during the finishing phase and MEP phase in an infrastructure project and the improvements on the project indicators (SPI and Percentage of Complete Plan), b) To describe the behaviours of the subcontractors during the implementation of LPS.

\section{KEY CONCEPTS}

\section{Last Planner System ${ }^{\circledR}$}

The LPS is a socio-technical production planning \& control project system that helps produce reliable workflow and rapid learning in the program, design, construction, and commissioning of projects. The principles of the system apply to any work requiring coordination between people. LPS is a structured collaborative process that dramatically improves coordination and the identification of constraints on projects through effective conversations, shared understanding, and reliable promising. This improves value on the project in safety, quality, team morale (mood), and productivity, reducing schedule \& cost. (Ebbs and Pasquire, 2019). Also, LPS promotes conversations between foremen and site-management at appropriate levels of detail, and before issues become critical. These conversations increase the chance that workflows and recognizes that personal relationships and peer pressure are critical to that process. (Mossman,2017). LPS has 05 elements: a) Master Scheduling (set milestones and phases durations \& overlaps), b) Phase Pull Planning (specify handoffs \& conditions of satisfaction between processes within phases), c) Lookahead Planning (task breakdown, constraint analysis, and removal, collaborative design of operations), d) Commitment Planning (make reliable promises, underloading resources, visual controls, daily huddles), and e) Learning (Analysis of breakdowns, Measure indicators: Percentage Plan Complete, Task Make Ready y Task Anticipated; the use of 5 Whys to identify countermeasures, act to prevent reoccurrence, PDCA: Plan-Do-Check-Act). (Ballard and Tommelein 2016).

\section{Pull Planning}

It is a collaborative planning process where project performers work together to design the process to deliver a milestone. The term "Pull Planning" refers to the lean concept of "pull" as a request from downstream as opposed to the top-down "push" as applied in a traditional practice. (Tsao, Drapper and Howell,2014). Also, pull planning creates agile teams that can respond to changing conditions or creating multiple plans for the same activity that eliminates unnecessary work and reduces durations. (Ebbs and Pasquire, 2019).

\section{Visual Management}

Visual Management (VM) is an important management strategy and a fundamental element of the Toyota Production System that creates highly visual (sensory) information 
fields from which people can pull information for an augmented self-management and control (Tezel et al. 2013). One of the direct outcomes of VM is an increase in the communication ability of process elements, which is defined as process transparency (Formoso et al., 2002).

\section{BIG ROOM}

The concept of "Big Room", also known by the Japanese word "Obeya" is linked with the concept of co-location, which in Toyota refers to the practice of locating multidisciplinary teams in the same place to improve communication and creativity in the process of automotive design. In the construction industry, the "Big Room" facilitates the implementation of The Last Planner ${ }^{\circledR}$ System (LPS) and Collaborative Planning. Under the background of LPS, the Big Room can be defined as the place where collaborative planning meetings are held, milestones plan, Pull Sessions, weekly meetings, and daily stand up meetings. The Big Room helps to encourage people to collaborate, improves the communication of the key information. People from many different disciplines and companies can get high quality interactions (Pons, 2019).

\section{METHODOLOGY OF IMPLEMENTATION}

The implementation of the Last Planner System started with the integration of subcontractors on the 37 th week of the project until the 64th week of the project. During the 1st week and 36th week, the General Contractor executed structural works with good results.

The methodology used in the development of this research was divided into 2 stages. Figure 1.

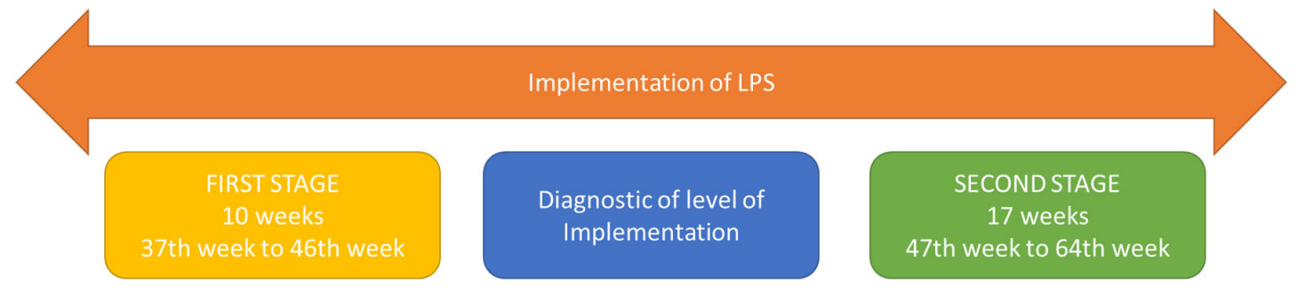

Figure 1: Stages of LPS implementation

- First Stage: This stage was about the implementation of LPS during 10 weeks of the Project. In this stage the subcontractors were trained in the use of LPS correctly, GC taught them to identify restrictions and made a correct look ahead. Also, the team identified key indicators in the Project: PPC (Percentage Plan Complete) and SPI. Alarcon et al. (2014) indicates that there is a close relationship between the variability of PPC, SPI, and the success of the projects. Consequently, the joint application of EVM and LPS could lead to a holistic progress measurement of a project considering both quantifiable metrics like schedule and costs but also factors like quality of workflow and collaboration. (Novinsky et al., 2018)

- Diagnostic: Balandron (2017) mentioned a tool developed by the Centro de Excelencia en Gestión de Producción de la Pontificia Universidad Católica, (GEPUC) that permits to evaluate the level of implementation of LPS in projects. 
Based on this tool the team identified twelve good practices in the implementation of LPS and opportunities to improve it.

- Second Stage: Based on the diagnose of the level of implementation GC prepare and implement improvements to increase the level of implementation. In this stage, the team applied visual management, big room, and other tools to increase collaboration and communication on the Project.

\section{First Stage AND Diagnostic}

In this stage, General Contractor trained MEP subcontractors with the concepts of LPS such as look ahead, identify restrictions, weekly plans to get good results. However, the General Contractor faced certain problems with subcontractors:

- Low commitments, PPC (Percentage of Plan Complete) was around 50\% percent and SPI was descending (Figure 2).

- Lack of knowledge in last planner tools. (Shortfalls in identified constraints, weekly plan, daily plan)

- Low collaboration.

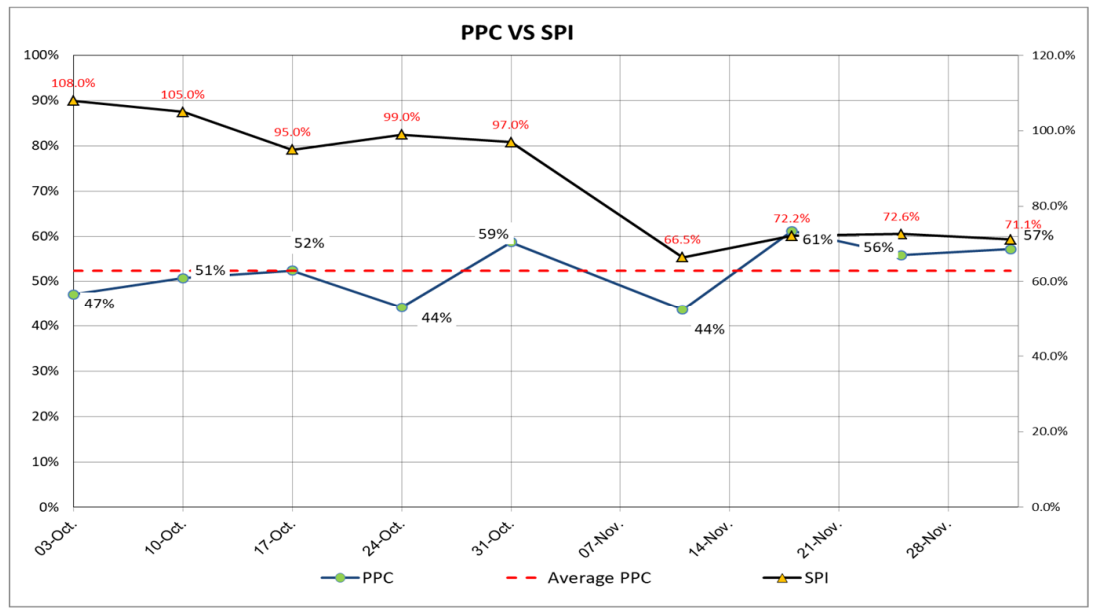

Figure 2: PPC vs SPI after 10th weeks of implementation

Based on this scenery, the team evaluated the level of implementation of LPS with the model proposed by Balandron (2017) and identified these problems in the implementation:

- Initial planning: In the case of initial planning, the master plan was not visible, so it is necessary to show it visibly to all the participants who are part of the meetings; and the milestone plan was not published among all participants in the planning sessions.

- Restrictions Management: Proper management of constraints was not being carried out in the project, which is leading to delayed commitments impacting task planning, this can be seen in the project's PAC and SPI.

- Short Term Planning: The structure of the meeting was published by email; however, it is necessary to establish on a wall the sequence of the meetings. Some subcontractors are in a learning period and are still learning to identify constraints and properly fill in the look ahead.

- Analysis of cause of non-compliance: A correct analysis of the CNC was not being carried out. There was a CNC survey, but was not updated 
- Corrective actions: There was no work being done on an analysis of corrective actions by type of subcontractor and the corrective actions being taken on the project were not recorded.

- Reliable commitments: Subcontractors were working on their plans and understanding the methodology as they have not worked on previous projects with the use of LPS.

- Visual Management: Everyday general contractor and subcontractors submitting daily plans, however, there were no panels promoting transparency on the planning site or in the meeting room.

- Phase Plan: Regarding the phase plan, it was not carried out, it was not updated and there was no record of commitments associated with the phase planning meeting. There was no culture in the project that allows collaborative planning to be developed.

- Measurement and control of indicators: Attendance Control of subcontractors was registered. Causes of Non-compliance and indicators were not published or updated.

- LPS planning meeting: The Weekly meeting happened on Fridays. The team established an adequate space for meetings. However, not all subcontractors were integrated. Some of them arrived early and others arrive late.

- Participants: The production manager, the venue manager used to participate. In some meetings, the client was invited to promote the transparency of the project. Subcontractors were involved, but not all of them arrived prepared.

The detail of each of the points can be found in the following graph (Figure 3).

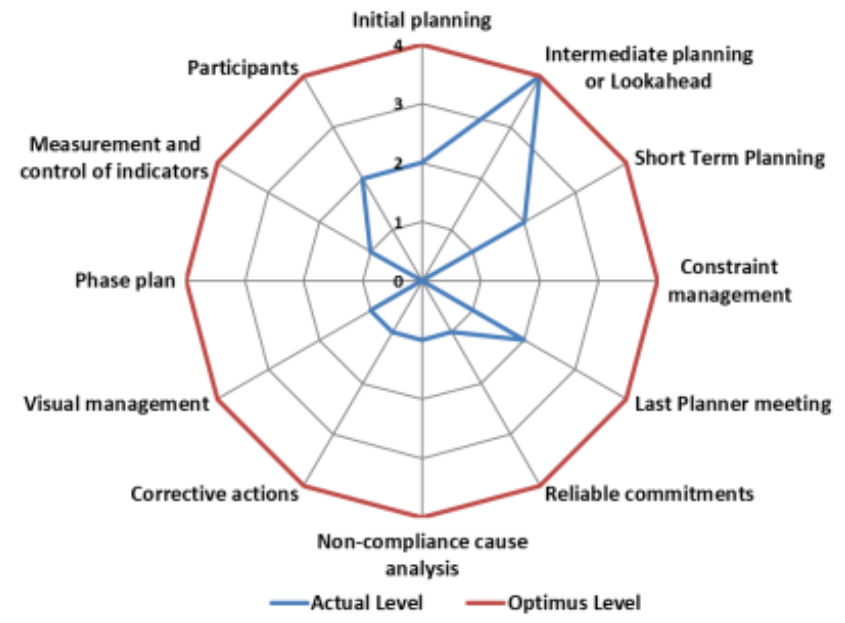

Figure 3: Evaluation of the level of implementation of LPS

\section{SECOND STAGE}

Based on the evaluation of the level of implementation. The team of the project implement some countermeasures to improve project indicators and level of implementation of LPS, these actions are described below: 


\section{Alignment of the Organization}

For the better implementation of the Last Planner in the project, the GC changed the positions in the venue. They assigned a Last Planner Facilitator; he had the responsibility to collect Look Ahead of subcontractors, collect Non-Completion causes, suggest countermeasures, and support the facilitation of the Last Planner Meetings.

\section{Pull Planning Meeting}

Pull Planning Meeting was implemented at the 52nd week of work before this GC use visual panels to improve the coordination. Pull Planning session was divided into 3 stages:

- Stage 1: In these stage participants were MEP and communication subcontractors. Duration: 02 hours. (Figure 4).

- Stage 2: In these stage participants were facade subcontractors (curtain wall, Huaca wall, piping, electrical, and metallic structure subcontractor). This meeting took 01:30 hours.

- Stage 3: Finishes subcontractors, this meeting took 01:00 hour.

At the beginning, the subcontractors were not familiar with this methodology.

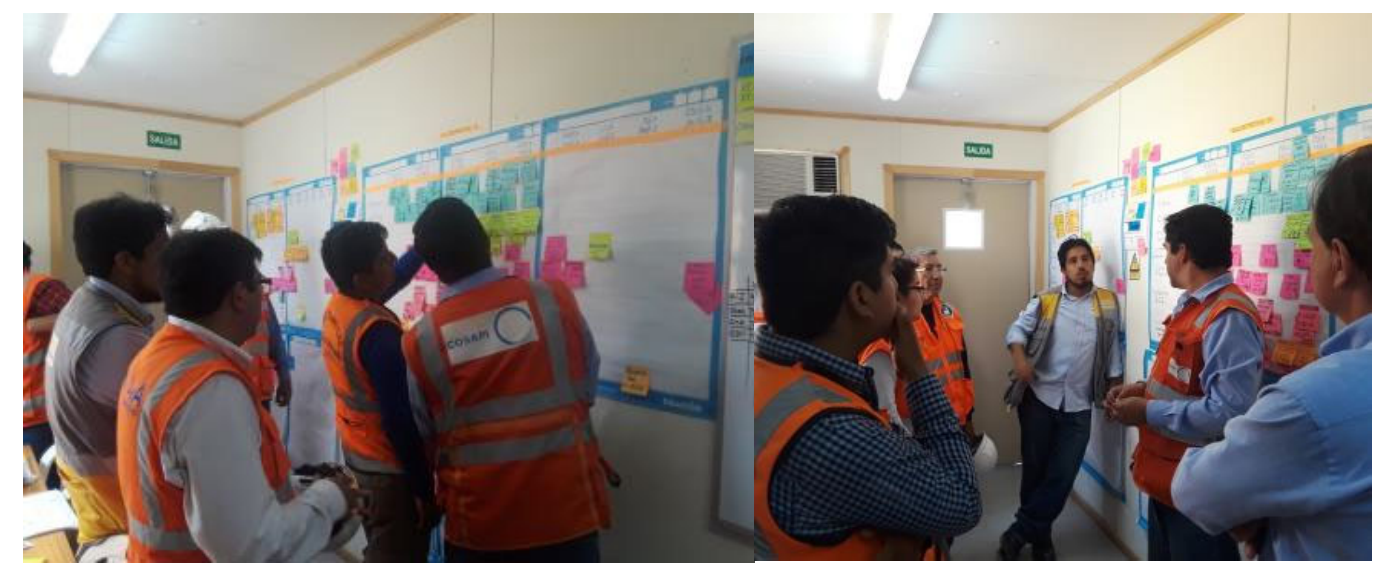

Figure 4: MEP subcontractors and communication subcontractor in Pull Planning Meeting

\section{Make Ready Planning}

In the case of Make ready planning, GC used the pull planning panels to support the planning because it helped to see all the planning easily. Also, it used a look-ahead planning meeting to identify the restrictions of works and coordinate very well the activities. GC created a culture with subcontractors based on the schedule in pull planning meetings.

Also, GC made a big room to increase the collaboration and It taught subcontractors to make a correct look ahead because most of them were beginners in the application of this tool, they usually faced problems with restrictions, they didn't identify restrictions of the works; they didn't take corrective actions and non-completions actions, they didn't break down correctly the activities, they didn't report PPC indicators. After 04 weeks of work, they improved the quality of look ahead and could help other subcontractors, to take better decisions. The venue team supported the restrictions identification with a risk matrix, Allison et al. (2018) suggest using a risk matrix to have better outcomes in construction. The venue team had a weekly meeting to share risk matrix with the construction manager and with this support they solved restrictions. 


\section{Weekly Work Planning}

For this meeting, GC sent an e-mail and WhatsApp messages to all subcontractors with the agenda of the meeting two days before the meeting. In this meeting at the beginning, GC used a paper and assign a color for subcontractors, every subcontractor painted their own work and marked the sector to anticipate interferences. After 03 weeks GC implemented a whiteboard with the shape of the project, assigned a color marker for every subcontractor and it used the board to mark the area of work. It helped to visualize the work and interferences. (Figure 5).

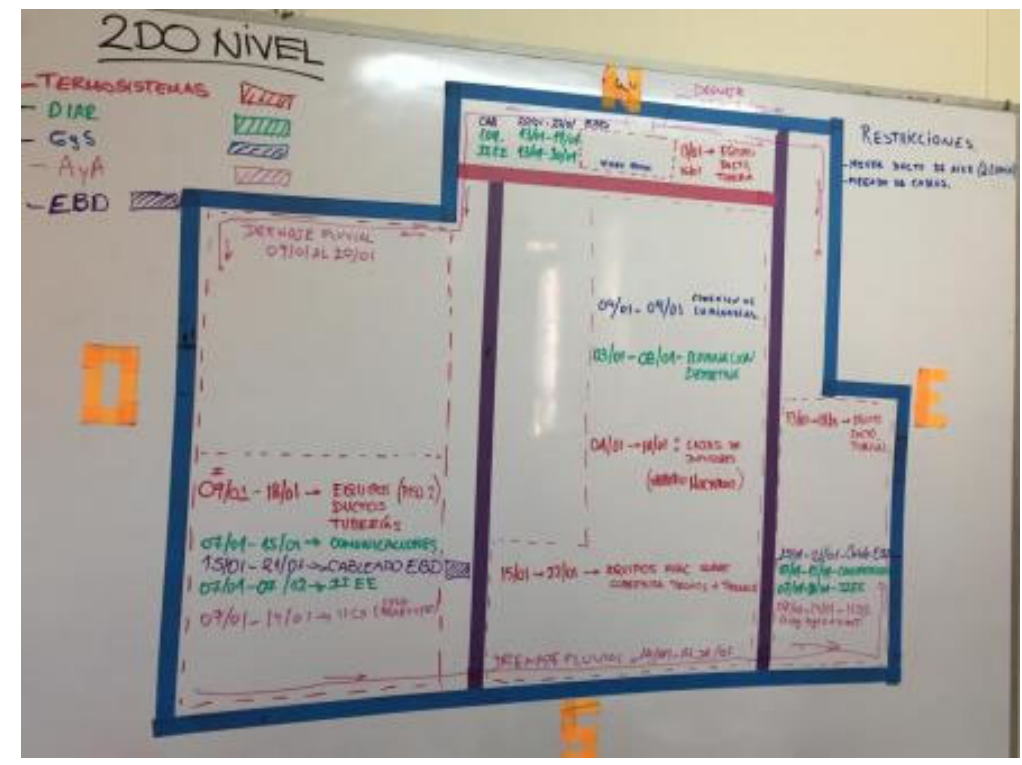

Figure 5: Visual Panel after MEP subcontractors and communication subcontractor meeting

Finally, with the coordination of facade works, GC used a whiteboard with post-it notes to improve the planning meeting; GC assigned a color of post-it notes to every subcontractor to mark its own location of work. (Figure 6).

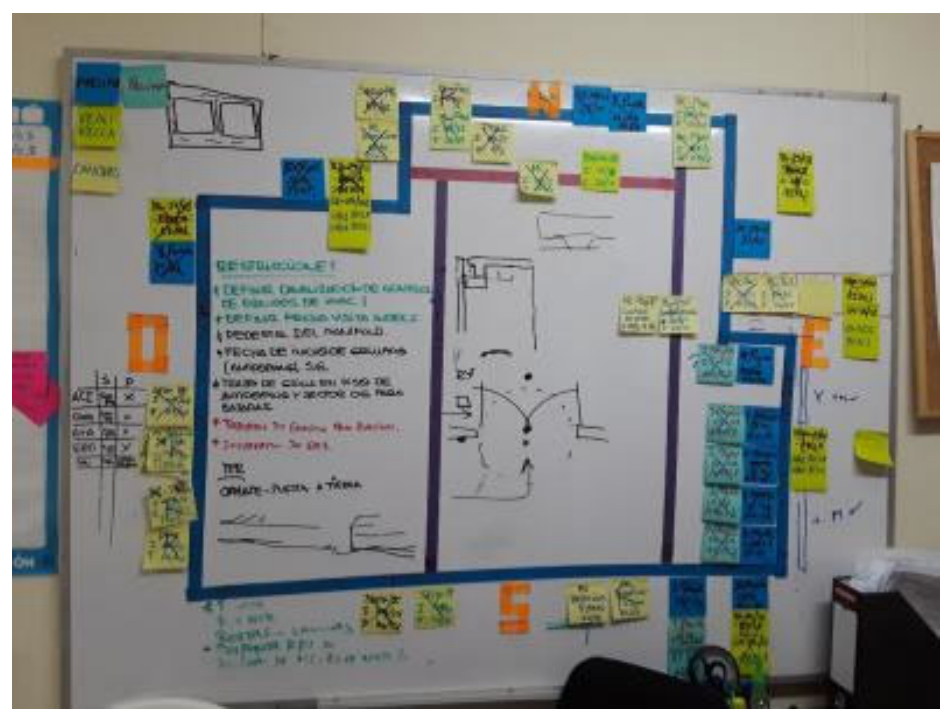

Figure 6: Visual Panel facade subcontractors meeting 


\section{Daily Planning}

Cruz (2017) used the design thinking to promote better flow communication in residential projects. He discovered that foremen feel comfortable to use WhatsApp as a communication tool, he also analyzed other communication IT. He systematizes the language in WhatsApp conversations. In the case of the project, the Client created a group to increase the transparency in the field; everyday General Contractor uploaded the Daily Plan to the awareness of the client. (Figure 7).

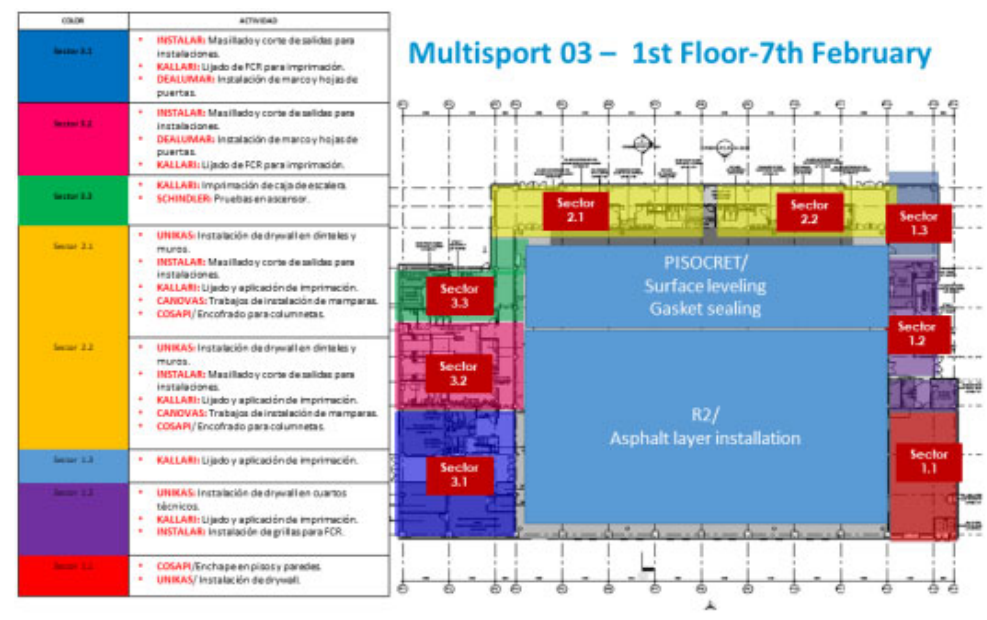

Figure 7: Daily Plan that General Contactor sent to client

These practices replied with the principal subcontractors (Sanitary works, finishes, steel structure and other), based on this success and to increase the transparency of the general contractor, 2 WhatsApp groups were created on the critical activities in the project:

- Facade works: In this, GC needed to coordinate simultaneously between 06 subcontractors (curtain wall, Huaca wall, electrical. Plumbing, metal structure, facade subcontractor).

- Ceiling: In this case, the ceiling subcontractor needed that other subcontractor finishes their work to close the ceiling. He depends on HVAC subcontractor, communication subcontractors, firewater subcontractor, electrical, plumbing subcontractors.

\section{RESULTS}

After the implementation of countermeasures, Figure 8 shows that the PPC was increased during the time. The average PPC was near $70 \%$ and the variability reduces. The SPI of the project increased weekly and it permitted to deliver the project on time, too. 


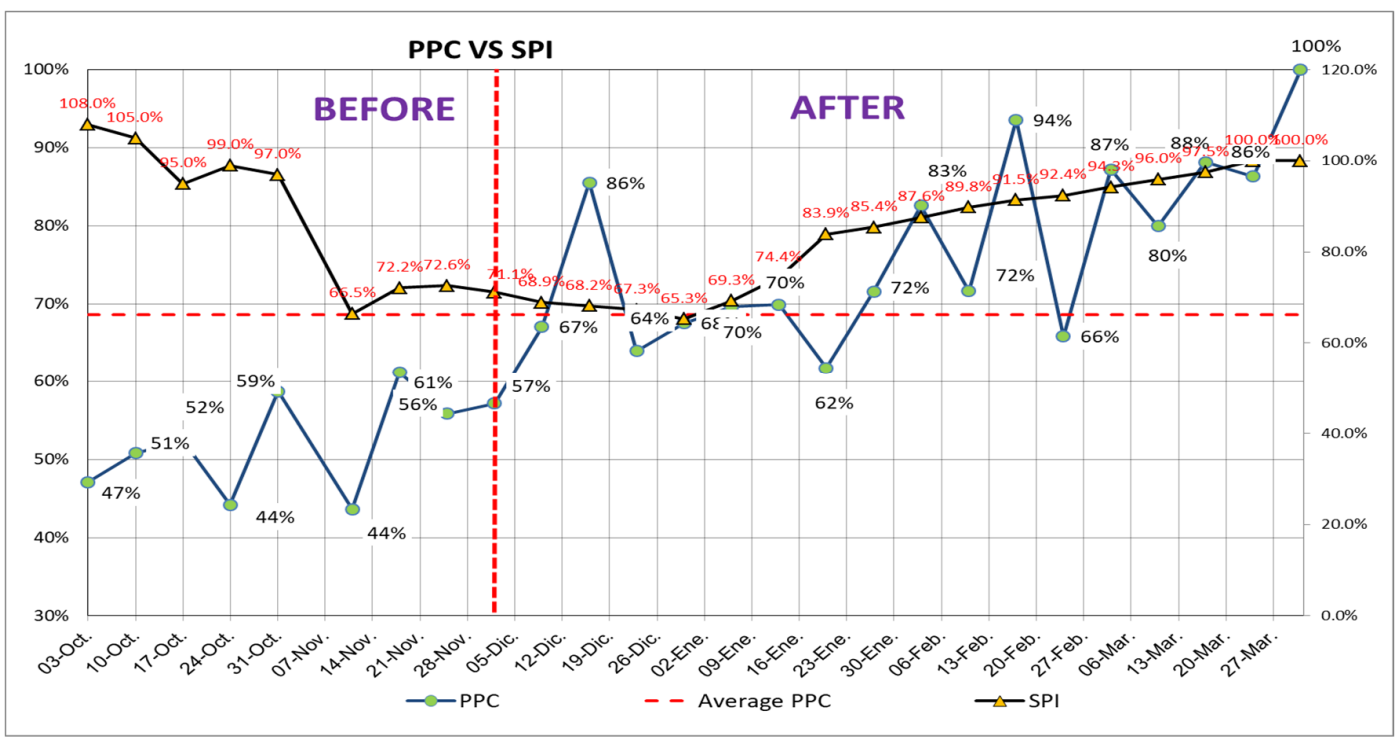

Figure 8: PPC VS SPI during $27^{\text {th }}$ weeks of implementation

Also, the level of implementation of LPS increased significantly. However, GC didn't reduce the gap in some points of evaluation:

- Restrictions Management: In the case of restrictions GC identified some on them on the meetings and GC used a risk matrix to evaluate the impact of the restrictions of the schedule.

- Analysis of cause of non-compliance: A correct analysis of the CNC was not carried out. Some subcontractors only sent their look ahead planning and completed causes of non-compliance but they didn't analyze.

- Corrective actions: Some corrective actions were registered but not totally. The owner of the project usually indicated to General Contractor to send corrective actions of critical activities that could impact the final milestone of the project.

- Measurement and control of indicators: During the Project, General Contractor registered SPI and PPC. However, in a future project, GC can use some indicators, Samad et al. (2017) proposed TMR (Task Make Ready), PCR (Percentage Constraints Remove).

- LPS planning meeting: Weekly meeting happened on Fridays. To improve the meeting GC could prepare a coffee break and reduce the use of cell phones during the meeting. 


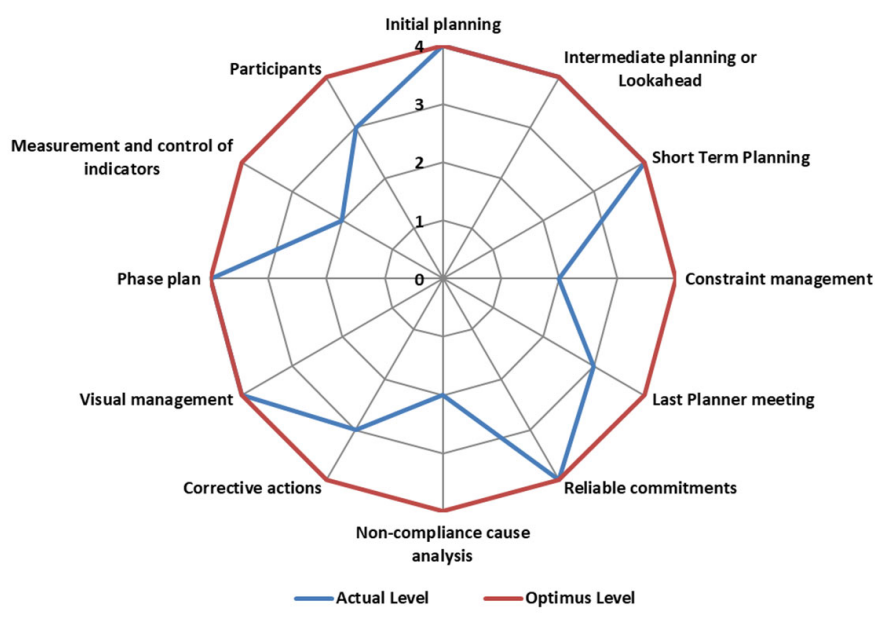

Figure 9: Evaluation of the level of implementation of LPS

\section{CONCLUSIONS}

These are the main conclusions of the study that was carried out:

- The implantation of a person as the Last Planner Facilitator helped field engineers and Venue Manager to improve the communication with the subcontractors.

- Indicators of the project (SPI and PPC) improve with the correct application of LPS. It's important to have tools to evaluate the level of implementation of LPS, so the team can act quickly before the variability affects the project. The team suggest considering more indicators related to LPS.

- Pull Planning Meetings helped to increase the collaboration between trades and noticed the dependences between subcontractors. Other important benefits were the identification of multiple restrictions of works.

- Visual Management was permitted to increase the collaboration, communication, and transparency between subcontractors, owner, and the General Contractor. (Figure 10).

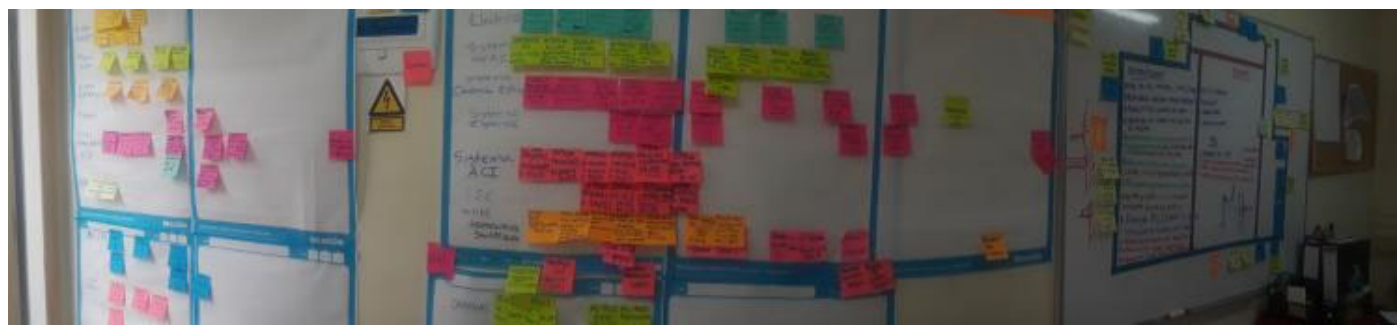

Figure 10: Visual Panels in Big Room

Fauchier and Alves (2013) observed behaviors during the implementation of the last planner system. In this implementation, the Venue team noticed that subcontractors, client and general contractor experiment these behaviors:

- Learning, continuous improvement and goal-driven behaviors: Subcontractor was aligned with the milestones of the project, also they learned about the use of the last planner system and made a correct look ahead. 
- Open participation/communication, transparency: They were free to participate in the meeting. At half of the implementation, the subcontractor arrives with restrictions that depend on other subcontractors and in the meeting other subcontractors made committed to solve these constraints.

- Reliable promising: PPC in the project increased with the pull planning meetings and use of visual panels (Figure 10).

\section{ACKNOWLEDGMENTS}

The authors would like to thank the subcontractors who achieved the milestones of the project and the engineer Julio Guinand, site manager of the Venue, for their support in the implementation of the Last Planner System ${ }^{\circledR}$.

\section{REFERENCES}

Alarcón, L. F. , Salvatierra, J. L. \& Letelier, J. A. 2014. "Using Last Planner Indicators to Identify Early Signs of Project Performance.” In:, Kalsaas, B. T., Koskela, L. \& Saurin, T. A., 22nd Annual Conference of the International Group for Lean Construction. Oslo, Norway, 25-27 Jun 2014. pp 547-558

Allison, M., Ashcraft, H., Cheng, R., Klawens, S., \& Pease, J. 2018. "Integrated Project Delivery: An Action Guide for Leaders". [online] Available at: $<$ https://leanipd.com/integrated-project-delivery-an-action-guide-for-leaders/> [Accessed: 18th January 2020].

Baladrón, C. 2017. Evaluación de impactos de la implementación de metodologías lean en proyectos de desarrollo minero en construcción.[Impact evaluation of the implementation of lean methodologies in mining development projects under construction] Msc. Pontifical Catholic University of Chile (in Spanish).

Ballard, G., \& Tommelein, I. 2016. "Current process benchmark for the last planner system”. Lean Construction Journal, 89, 57-89.

Cruz Calcina, J. J. 2017. Optimización de flujo de información usando herramienta TIC en la etapa de acabados de un proyecto inmobiliario en Lima.[Optimization of information flow using the TIC tool in the finishing stage of a real estate project in Lima] BSc. National University of Engineering of Peru (in Spanish).

Ebbs, P. \& Pasquire, C. 2019. A Facilitators ' Guide to the Last Planner ${ }^{\circledR}$ System: A Repository of Facilitation Tips for Practitioners, Nottingham Trent University.

Fauchier, D. \& Alves, T. C. L. 2013, "Last Planner ${ }^{\circledR}$ System Is the Gateway to Lean Behaviors". In:, Formoso, C. T. \& Tzortzopoulos, P., 21 th Annual Conference of the International Group for Lean Construction. Fortaleza, Brazil, 31-2 Aug 2013. pp 559568

Formoso, C. T., Santos, A. D. and Powell, J. 2002. "An Exploratory Study on the Applicability of Process Transparency in Construction Sites" J. of Constr.Research, 3(1) 35-54.

Gestion, 2019. ¿Qué tipo de contrato se usó en los Panamericanos 2019 para agilizar la construcción de las sedes deportivas? [online] Available at: $<$ https://gestion.pe/economia/que-tipo-de-contrato-se-uso-en-los-panamericanos2019-para-agilizar-la-construccion-de-las-sedes-deportivasnoticia/?ref=gesr $>$ [Accessed: 5th January 2020]. 
Pons J. 2019. The 5 Benefits of the Big Room with the Last Planner ${ }^{\circledR}$ System. Available at: $<$ https://leanconstructionblog.com/THE-5-BENEFITS-OF-THE-BIG-ROOM-INLAST-PLANNER-SYSTEM.html> Accessed: [17th January 2020]

Mossman, A., 2017. "Collaborative Planning: $5+1$ Crucial and Collaborative Conversations for Predictable Design and Construction Delivery" [online] Available at: $<$ https://www.researchgate.net/publication/321804312_Last_Planner_5_1_crucial _collaborative_conversations_for_predictable_design_construction_delivery_Dec_2 017> [Accessed: 20th January 2020].

Murguía, D. , Brioso, X. \& Pimentel, A. 2016. “Applying Lean Techniques to Improve Performance in the Finishing Phase of a Residential Building”. In:, 24th Annual Conference of the International Group for Lean Construction. Boston, USA, 20-22 Jul 2016.

Murguia, D. 2019. "Factors Influencing the Use of Last Planner System Methods: An Empirical Study in Peru”. In:, Proc. 27th Annual Conference of the International Group for Lean Construction (IGLC). Dublin, Ireland, 3-5 Jul 2019. pp 1457-1468

Novinsky, M. , Nesensohn, C. , Ihwas, N. \& Haghsheno, S. 2018. "Combined Application of Earned Value Management and Last Planner System in Construction Projects". In:, 26th Annual Conference of the International Group for Lean Construction. Chennai, India, 18-20 Jul 2018. pp 775-785

Samad, G. E. , Hamzeh, F. R. \& Emdanat, S. 2017. "Last Planner System - the Need for New Metrics". In:, 25th Annual Conference of the International Group for Lean Construction. Heraklion, Greece, 9-12 Jul 2017. pp 637-644

Tezel, A. , Koskela, L. J. \& Tzortzopoulos, P. 2013. "Visual Management in Industrial Construction a Case Study. In:, Formoso, C. T. \& Tzortzopoulos, P., 21th Annual Conference of the International Group for Lean Construction. Fortaleza, Brazil, 31-2 Aug 2013. pp 471-480

Tsao, C. C. , Draper, J. \& Howell, G. A. 2014. "An Overview, Analysis, and Faciliation Tips for Simulations That Support and Simulate Pull Planning”. In:, Kalsaas, B. T., Koskela, L. \& Saurin, T. A., 22nd Annual Conference of the International Group for Lean Construction. Oslo, Norway, 25-27 Jun 2014. pp 1483-1494. 